\title{
Selective cell cycle arrest and induction of apoptosis in human prostate cancer cells by a polyphenol-rich extract of Solanum nigrum
}

\author{
AKBAR NAWAB ${ }^{1,2,4}$, VIJAY S. THAKUR ${ }^{1,2}$, MOHAMMAD YUNUS $^{4}$, ABBAS ALI MAHDI $^{5}$ and SANJAY GUPTA ${ }^{1-3}$ \\ ${ }^{1}$ Department of Urology, Case Western Reserve University; ${ }^{2}$ The Urology Institute, University Hospitals Case Medical \\ Center; ${ }^{3}$ Case Comprehensive Cancer Center, Cleveland, OH 44106, USA; ${ }^{4}$ Department of Environmental \\ Sciences, Babasaheb Bhimrao Ambedkar University, Lucknow 226025; ${ }^{5}$ Department of \\ Biochemistry, King George's Medical University, Lucknow 226003, India
}

Received July 19, 2011; Accepted September 2, 2011

DOI: 10.3892/ijmm.2011.835

\begin{abstract}
Progression of prostate cancer is associated with escape of tumor cells from cell cycle arrest and apoptosis. Agents capable of selectively eliminating cancer cells by cell cycle arrest and/or induction of apoptosis offer a highly desirable approach. Here we demonstrate that a polyphenolic extract derived from ripe berries of Solanum nigrum (SN) differentially causes cell cycle arrest and apoptosis in various human prostate cancer cells without affecting normal prostate epithelial cells. Virally transformed normal human prostate epithelial PZ-HPV-7 cells and their cancer counterpart CA-HPV-10 cells, were used to evaluate the growth-inhibitory effects of the SN extract. SN treatment $(5-20 \mu \mathrm{g} / \mathrm{ml})$ of PZ-HPV-7 cells resulted in growth inhibitory responses of low magnitude. In sharp contrast, SN treatment of CA-HPV-10 cells increased cytotoxicity, decreased cell viability and induced apoptosis. Similar results were noted in the human prostate cancer LNCaP, 22Rv1, DU145 and PC-3 cell lines, where significant reductions in cell viability and induction of apoptosis was observed in all these cells, an effect independent of disease stage and androgen association. Cell cycle analysis revealed that $\mathrm{SN}$ treatment $(5-20 \mu \mathrm{g} / \mathrm{ml})$ resulted in a dosedependent $\mathrm{G} 2 / \mathrm{M}$ phase arrest and subG1 accumulation in the CA-HPV-10 but not in the PZ-HPV-7 cell line. Our results, for the first time, demonstrate that the SN extract is capable of selectively inhibiting cellular proliferation and accelerating
\end{abstract}

Correspondence to: Dr Sanjay Gupta, Department of Urology, Case Western Reserve University, 2109 Adelbert Road, Wood Research Tower, Cleveland, $\mathrm{OH}$ 44106, USA

E-mail: sanjay.gupta@case.edu

Abbreviations: DNA, deoxyribonucleic acid; PARP, poly (ADP-ribose) polymerase; HPLC, high performance liquid chromatography, SN, Solanum nigrum

Key words: apoptosis, DNA fragmentation, cell proliferation, prostate cancer, chemotherapy apoptotic events in prostate cancer cells. SN may be developed as a promising therapeutic and/or preventive agent against prostate cancer.

\section{Introduction}

A rational approach to cancer treatment is to selectively eliminate proliferating tumor cells via programmed cell death and spare quiescent or terminally differentiated cells $(1,2)$. Decreasing the rate of programmed cell death or apoptosis in defective cells and increasing that of the cell cycle affords cancer cells a survival advantage and the ability to sustain and proliferate (2). In the United States, prostate cancer is highly prevalent and remains the second leading cause of cancerrelated deaths among men (3). The major cause of mortality from this disease is metastasis of androgen-refractory cancer cells that fail to respond to hormone ablation therapy (4). As surgery and current chemotherapeutic options seem to be inadequate in curing or controlling prostate cancer, there is a pressing need for identification of novel agents for the management of this disease. Natural phytochemicals derived from dietary sources or medicinal plants have gained significant recognition in the control and containment of carcinogenesis and are considered a practical approach in disease prevention and therapy (5).

Solanum nigrum L. (Solanaceae) or 'Black nightshade' is an herbal plant indigenous to Southeast Asia and is commonly used as traditional folk medicine believed to possess promising biological activity (6). Certain parts of the plant have been used as a hepatoprotective agent to cure inflammation and edema $(7,8)$. The water extracts of Solanum nigrum (SN) have been shown to exert cytoprotection against gentamicininduced toxicity in Vero cells, suppress oxidant-mediated DNA damage and induce necrosis in SC-M1 stomach cancer cells $(9,10)$. The SN extract has been shown to inhibit 12-O-tetradecanoylphorbol-13-acetate-induced tumor promotion in MCF-7 cells and to have anti-neoplastic activity against sarcoma in mice (11). It has also been reported that an ethanolic extract from fruits of SN could inhibit proliferation of human MCF-7 breast cancer cells, and induce cell death by 
apoptosis $(11,12)$. Recent studies demonstrate that an ethanolic extract of SN was protective against chemical-induced hepatic injury and early hepatocarcinogenesis through overexpression of glutathione S-transferases and other phase II antioxidant enzymes (13). Extracts from whole plants of SN have been reported to result in hepatoma cell death by inducing autophagy and apoptosis and to inhibit cell growth of HepG2 hepatocarcinoma cells by inducing G2/M phase cell cycle arrest (14). These studies suggest that SN could exert its anti-neoplastic activity as a cancer preventive and therapeutic agent. However, there is limited information about whether SN exerts selective toxicity to cancer cells with minimal damage to normal cells, an effective strategy for eliminating cancer cells. This study provides the first evidence that aqueous polyphenolic-rich SN extract at microgram concentrations imparts differential anti-proliferative and apoptotic effects in human prostate carcinoma cells vs. non-cancerous cells.

\section{Materials and methods}

Preparation of Solanum nigrum extract. The ripe berries of Solanum nigrum L. were purchased from The State Unani Tibbya College, Lucknow, India. The plants were authenticated by the Department of Pharmacognosy, National Botanical Research Institute, Lucknow, India, where the voucher specimen has been deposited. The ripe berries were weighed and crushed to powder with a mortar and pestle, and a 5\% $(\mathrm{w} / \mathrm{v})$ suspension was prepared in a flask by adding distilled hot boiling water. The flask was then placed on a shaker (200 rpm) for $4 \mathrm{~h}$, and the temperature was maintained at $37^{\circ} \mathrm{C}$. Subsequently, the flask was brought to room temperature and then the suspension was filtered through a series of Whatman filters and finally passed through a $0.22 \mu \mathrm{m}$ filter (Millipore, Billerica, MA). The filtered aqueous extract was lyophilized on a Speed Vac and the residue was used for further experiments.

Cell culture. The virally transformed PZ-HPV-7 cells derived from normal tissue of the peripheral zone of the prostate and immortalized by transfection with the HPV-18 virus as well as their cancer counterpart CA-HPV-10 cells and the other human prostate cancer cells, 22Rv1, LNCaP, DU145 and PC-3, were obtained from the American Type Culture Collection (Manassas, VA). All cells were cultured in appropriate culture medium at $37^{\circ} \mathrm{C}$ in a humidified atmosphere of $5 \% \mathrm{CO}_{2}$.

Composition analysis. The polyphenolic content present in the SN extract was analyzed according to the Folin-Ciocalteu method as previously described (15). Briefly, $0.1 \mathrm{mg}$ of lyophilized material was dissolved in $1 \mathrm{ml}$ distilled water and the solution was scanned from 200-750 nm on FluoStar Omega Spectrophotometer (BMG Labtech) and then subjected to absorbance at $750 \mathrm{~nm}$ using gallic acid as a standard. In the next step, aqueous SN extract was analyzed on an Agilent 1200 HPLC system (Agilent Technologies, Santa Clara, CA) using a C 18 column. The mobile phase consisted of acetonitrile and water as the isocratic solvent $(30: 70, \mathrm{v} / \mathrm{v})$ maintained at a flow rate of $1 \mathrm{ml} / \mathrm{min}$ with an injection volume of $5 \mu \mathrm{l}$ and a run time of $8 \mathrm{~min}$ as previously described (16). The resulting aqueous SN extract was loaded onto a $300 \mu \mathrm{m}$ ID x 5 mm C18, PepMap nano reverse phase (RP) trapping column to pre-concentrate using UltiMate-3000 (Dionex, Sunnyvale, CA). The sample was further analyzed on a $75 \mu \mathrm{m}$ ID x $15 \mathrm{~cm} \mathrm{C18,} \mathrm{PepMap}$ reverse phase nano separation column using the nano separation platform UltiMate-3000. Extract mixtures eluted from the column with the final gradient of acetonitrile of $20-80 \%$ for 30 min by mixing solvents A ( $100 \%$ water, $0.1 \%$ formic acid) and $\mathrm{B}$ (80\% acitonitrile, $20 \%$ water, $0.1 \%$ formic acid) were introduced into an LTQ FT mass spectrometer (ThermoFisher Scientific, San Jose, CA). The instrument was equipped with a nano spray ion source with a needle voltage of $2.4 \mathrm{kV}$. MS and tandem MS spectra were acquired in the positive ion mode, with the following acquisition cycle: a full scan recorded in the FT analyzer at resolution $\mathrm{R}=100,000$ followed by MS/MS of the eight most-intense ions in the LTQ analyzer.

Proliferation assay. The effect of the SN extract on cell proliferation was determined by the MTT [3-(4,5-dimethylthiazol-2-yl)-2, 5-diphenyl tetrazoliumbromide] assay and the growth inhibition was assessed as the percent viability where vehicle-treated cells were taken as $100 \%$ viable as previously described (16).

Light microscopy. PZ-HPV-7 and CA-HPV-10 cells were grown to $70 \%$ confluence and treated with $10-20 \mu \mathrm{g} / \mathrm{ml}$ concentrations of SN extract for $24 \mathrm{~h}$. The photographs were captured at $\mathrm{x} 40$ magnification using a phase-contrast inverse microscope (Olympus, Japan).

DNA fragmentation assay. The cells were grown to $\sim 70 \%$ confluence and treated with $5-20 \mu \mathrm{g} / \mathrm{ml} \mathrm{SN}$ extracts for $48 \mathrm{~h}$. Cells were then subjected to processing for DNA isolation and fragmentation assay. The bands were visualized under a UV transilluminator, followed by digital photography as previously described (16).

TUNEL assay. The TUNEL assay for quantification of apoptosis was performed in PZ-HPV-7 and CA-HPV-10 cells after treatment with a $5-20 \mu \mathrm{g} / \mathrm{ml}$ concentration of the SN extract for $48 \mathrm{~h}$ using the APO-BRDU apoptosis kit (Phoenix Flow Systems, San Diego, CA) according to the manufacturer's protocol using the EPICS-XL MCL flow cytometer.

Flow cytometry. Cell cycle analysis was performed in PZ-HPV-7 and CA-HPV-10 cells after treatment with 5-20 $\mu \mathrm{g} / \mathrm{ml}$ concentration of SN extract for $24 \mathrm{~h}$ using the EPICS-XL MCL flow cytometer and the Cell Quest analysis ModFit software as previously described (16).

Statistical analysis. The values are expressed as means \pm SD. The differences between the control and treated groups was determined by the Student's t-test, and P-values $<0.05$ were taken to denote significant differences.

\section{Results}

The spectroscopic scanning of aqueous SN derived from the ripe berries demonstrated a high peak at a wavelength of 200-400 nm (Fig. 1A). Analysis of the SN extract revealed that it contains $\sim 28 \%$ total polyphenols and this peak corresponds to lipids, steroids, vitamins and flavoproteins. Next 
A

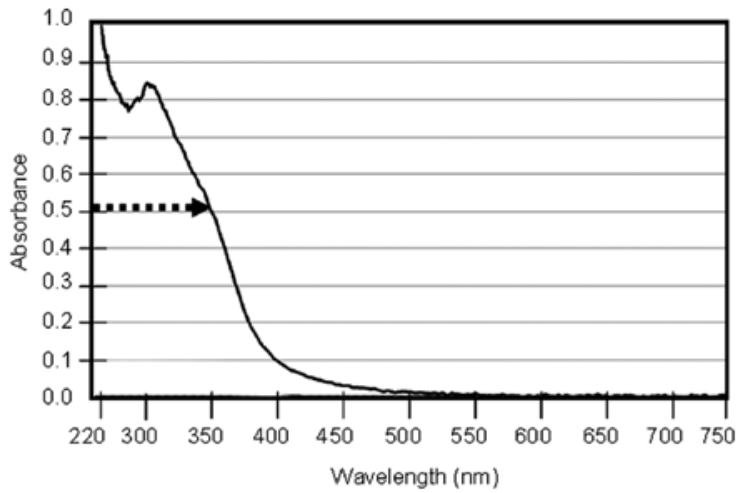

B
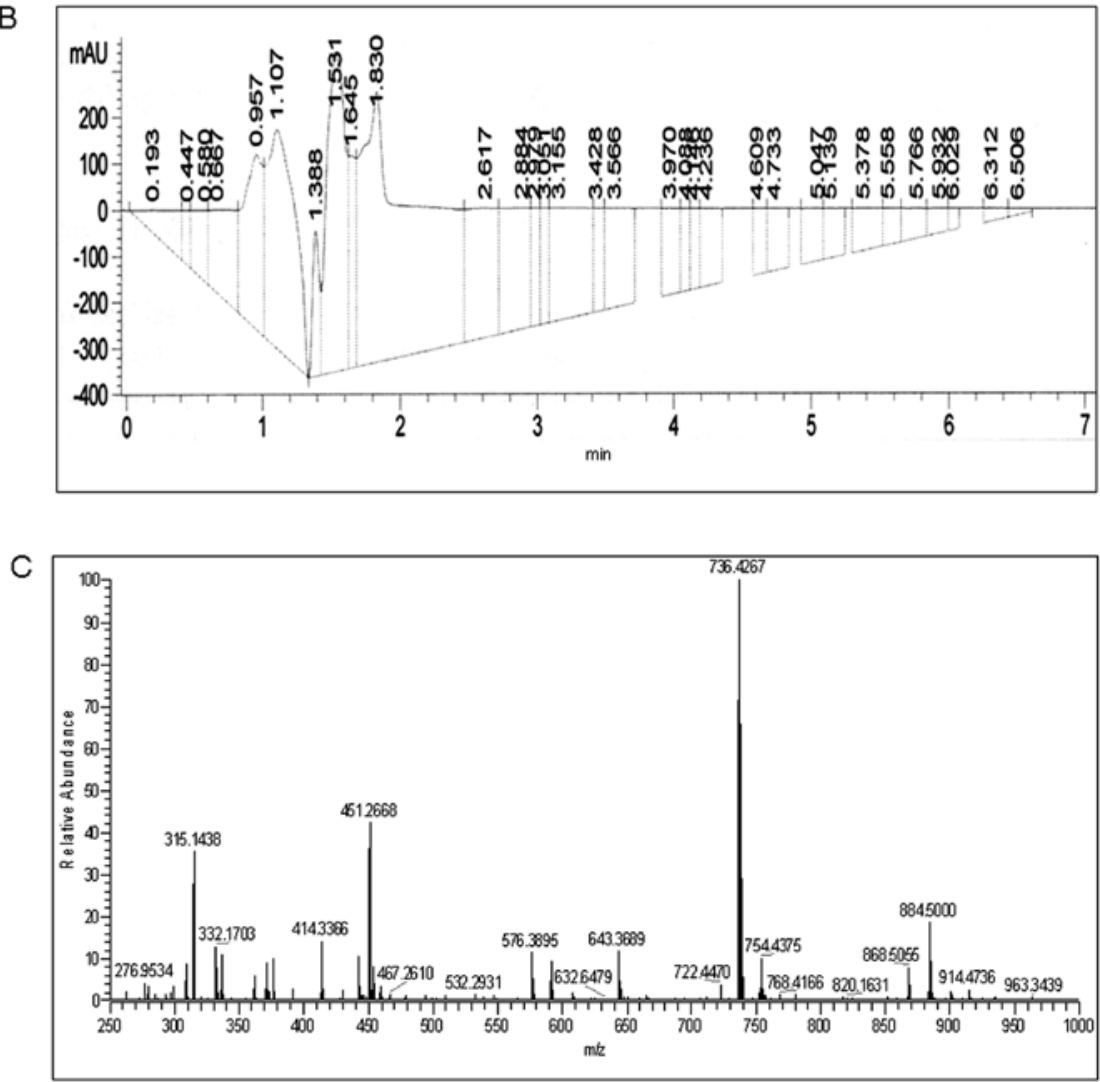

Figure 1. (A) UV spectrum of aqueous berry extract of Solanum nigrum (SN). The scan was obtained from 200-750 nm and then subjected to absorbance at $750 \mathrm{~nm}$ using gallic acid as standard. (B) HPLC chromatogram of an aqueous SN extract demonstrating the presence of various polyphenolic constituents. (C) Electrospray product ion mass spectra of SN extract. The ion chromatograms were extracted at $\mathrm{m} / \mathrm{z}$ corresponding to the molecular mass and structure of various polyphenolic compounds were detected. The details are described in the Materials and methods section.

we performed an HPLC scan at wavelengths ranging from 200-590 nm to determine the presence of various constituents in the SN extract (Fig. 1B). Altogether, a total of 30 peaks were recorded in the aqueous SN extract during the scanning process, most of which correspond to water soluble phenolics (Fig. 1B). Since the major polyphenols previously identified in $\mathrm{SN}$ are catechins and their derivatives, we narrowed the wavelength scan between 335 and $360 \mathrm{~nm}$, which identified five major peaks with retention times of 0.974 (23.4\%) 1.101 (33.1\%), 1.387 (7.5\%), 1.532 (18.9\%) and $1.823 \mathrm{~min}(17.1 \%)$ (data not shown). The peaks correspond to gallocatechin, caffeic acid, gallocatechin gallate, rutin and naringenin, respectively. Previous studies have identified several polyphenols in the extracts of leaves, stem and fruits of SN which include gallic acid, protocatechuic acid, epigallocatechin, chlorogenic acid, catechin, gentisic acid, vanillic acid, caffeic acid, syringic acid, epicatechin, epigallocatechin gallate, gallocatechin gallate, p-coumaric acid, ferulic acid, rutin, m-coumaric acid, narigenin, luteolin, myricetin, quercetin, apigenin, kaempferol, and hesperetin together with some anthocyanins (17). The other polyphenolic compounds might be present in the aqueous SN extract although their percentage might vary in our studies. The MS-MS data confirmed the presence of some steroidal glycosides and steroidal alkaloids which includes $\alpha$-solanine [molecular weight (MW) 867.49798; (M+H) 868.50525], solasodine [MW $413.32935(\mathrm{M}+\mathrm{H}) 414.33663]$, solasonine [MW 883.49289 (M+H) 884.50017], and solamargine [MW 883.49289 (M+H) 884.50017], respectively (Fig. 1C). 
A

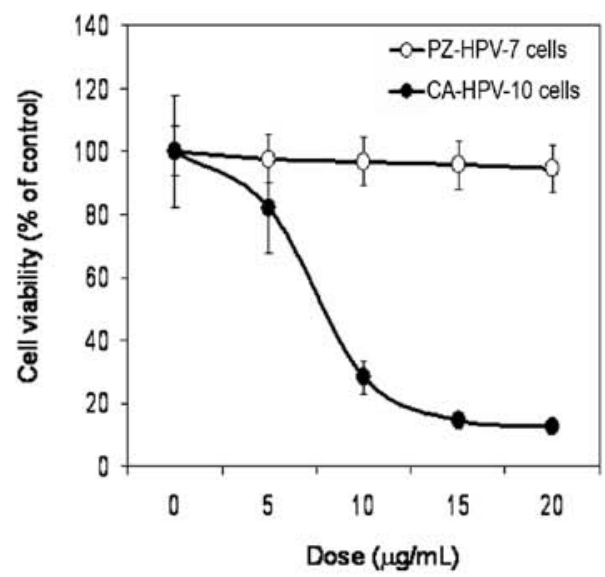

B
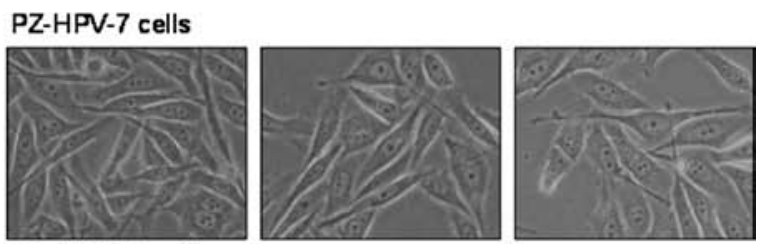

CA-HPV-10 cells

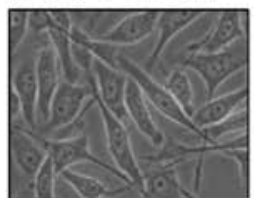

$0 \mu \mathrm{g} / \mathrm{mL}$

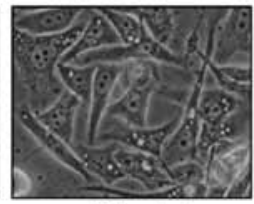

$10 \mu \mathrm{g} / \mathrm{mL}$

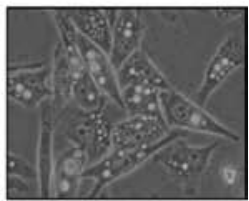

$20 \mu \mathrm{g} / \mathrm{mL}$

C

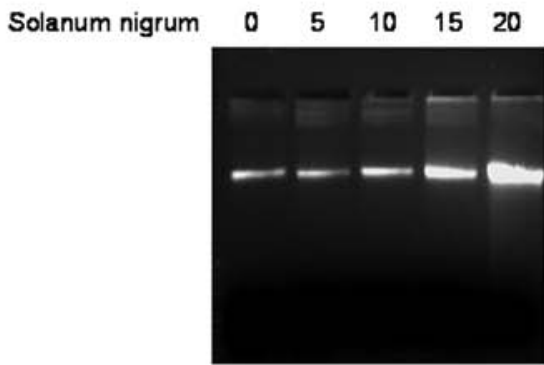

PZ-HPV-7 cells

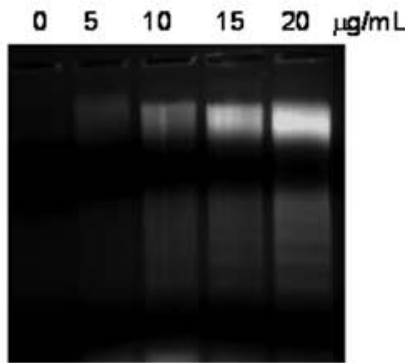

CA-HPV-10 cells

Figure 2. (A) Effect of SN extract on cell viability in non-cancerous PZ-HPV-7 cells, and their cancer counterpart CA-HPV-10 cells. The cells were exposed to the specified concentration of SN extract for $24 \mathrm{~h}$, and viability of the cells was determined by the MTT assay. Cell viabilities are depicted as percentages; vehicle-treated cells were regarded as 100\% viable. The data represent the mean of 3 experiments performed in triplicate. (B) Light microscopy images of virally transformed normal human prostate epithelial PZ-HPV-7 cells and their cancer counterpart CA-HPV-10 cells treated with aqueous SN extract. Treatment of CA-HPV-10 cells with SN extract exhibits morphological changes consistent with apoptosis, whereas no such morphological changes were observed in PZ-HPV-7 cells. (C) DNA fragmentation by SN extract in CA-HPV-10 cells. The cells were treated with 5-20 $\mu \mathrm{g} / \mathrm{ml}$ concentration of SN and $48 \mathrm{~h}$ later, the cells were collected, DNA was isolated and subjected to agarose gel electrophoresis, followed by visualization of bands under UV light. The PZ-HPV-7 cells did not indicate DNA fragmentation by SN extract. The details are described in the Materials and methods section.

Next we evaluated the growth inhibitory response of the aqueous $\mathrm{SN}$ extract in virally transformed prostate epithelial PZ-HPV-7 cells and carcinoma CA-HPV-10 cells obtained from the same individual. Exposure of PZ-HPV-7 cells to SN exhibited a modest decrease of $5.5 \%$ in cell viability at the highest concentration of $20 \mu \mathrm{g} / \mathrm{ml}$. In contrast, treatment of prostate cancer CA-HPV-10 cells with $5-20 \mu \mathrm{g} / \mathrm{ml}$ resulted in 17.9-87.3\% decrease in cell viability. This demonstrates that cancer cells were more sensitive to $\mathrm{SN}$-mediated loss of cell viability which occurred at much lower doses and was more pronounced than PZ-HPV-7 cells (Fig. 2A). Prominent changes in cell morphology were observed $24 \mathrm{~h}$ after treatment with SN extract in prostate cancer CA-HPV-10 cells, which displayed blebbing, loss of cell membrane symmetry and attachment, cell shrinkage, nuclear fragmentation and chromatin condensation when viewed under a light microscope. However, the morphology of normal prostate epithelial PZ-HPV-7 cells remained unchanged after SN treatment (Fig. 2B).

To confirm that reduced cell viability and cell proliferation of prostate cancer CA-HPV-10 cells after treatment with the SN extract was due to cell apoptosis, we performed a DNA fragmentation assay. Our results demonstrate that treatment with $5-20 \mu \mathrm{g} / \mathrm{ml}$ of SN extract for $48 \mathrm{~h}$ caused fragmentation of nucleosomal DNA, a characteristic feature of apoptosis, in 

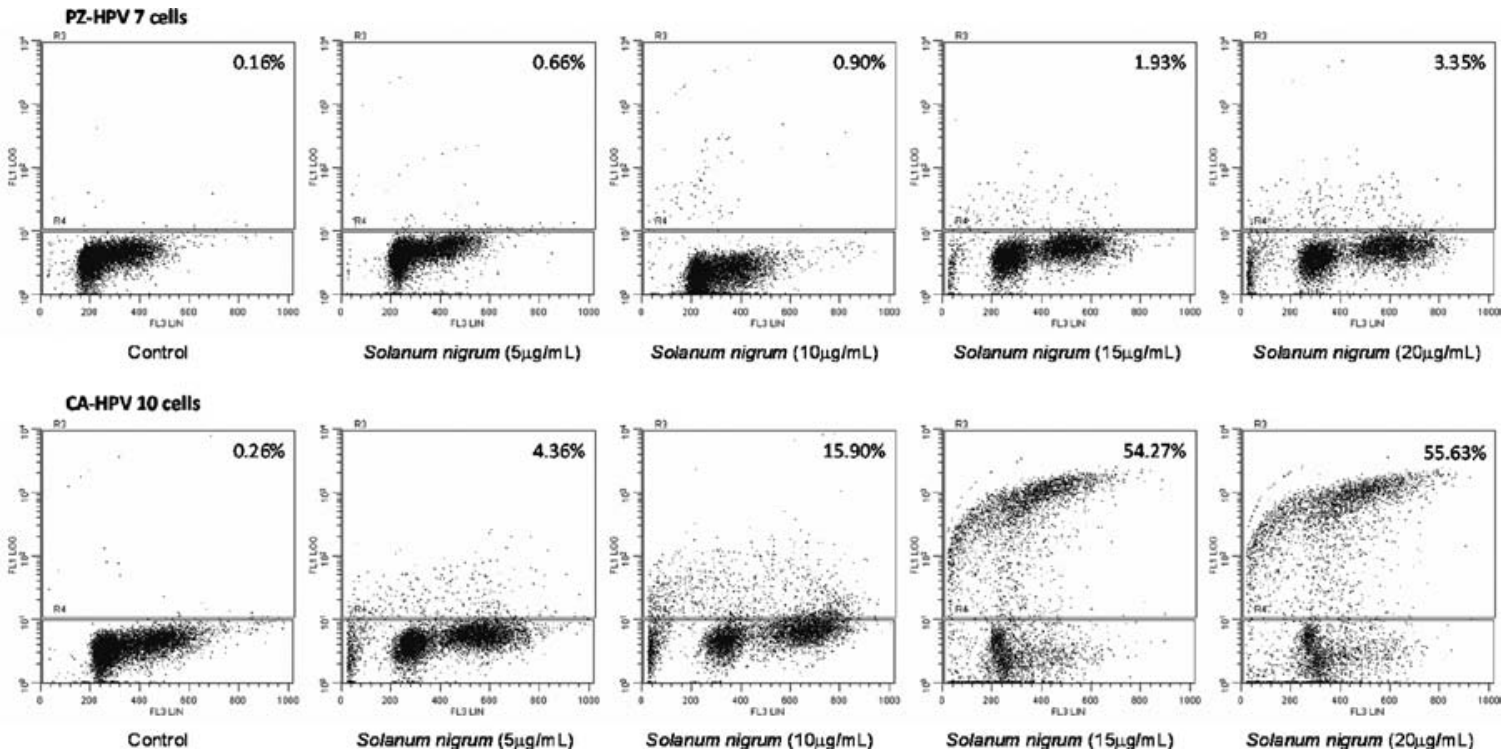

Figure 3. Effect of SN extract on induction of apoptosis in virally-transformed normal human prostate epithelial PZ-HPV-7 cells, and their cancer counterpart CA-HPV-10 cells. The cells were treated with $5-20 \mu \mathrm{g} / \mathrm{ml}$ concentration of SN extract for $48 \mathrm{~h}$ and the number of cells undergoing apoptosis was determined using the TUNEL assay. Details are described in the Materials and methods section.
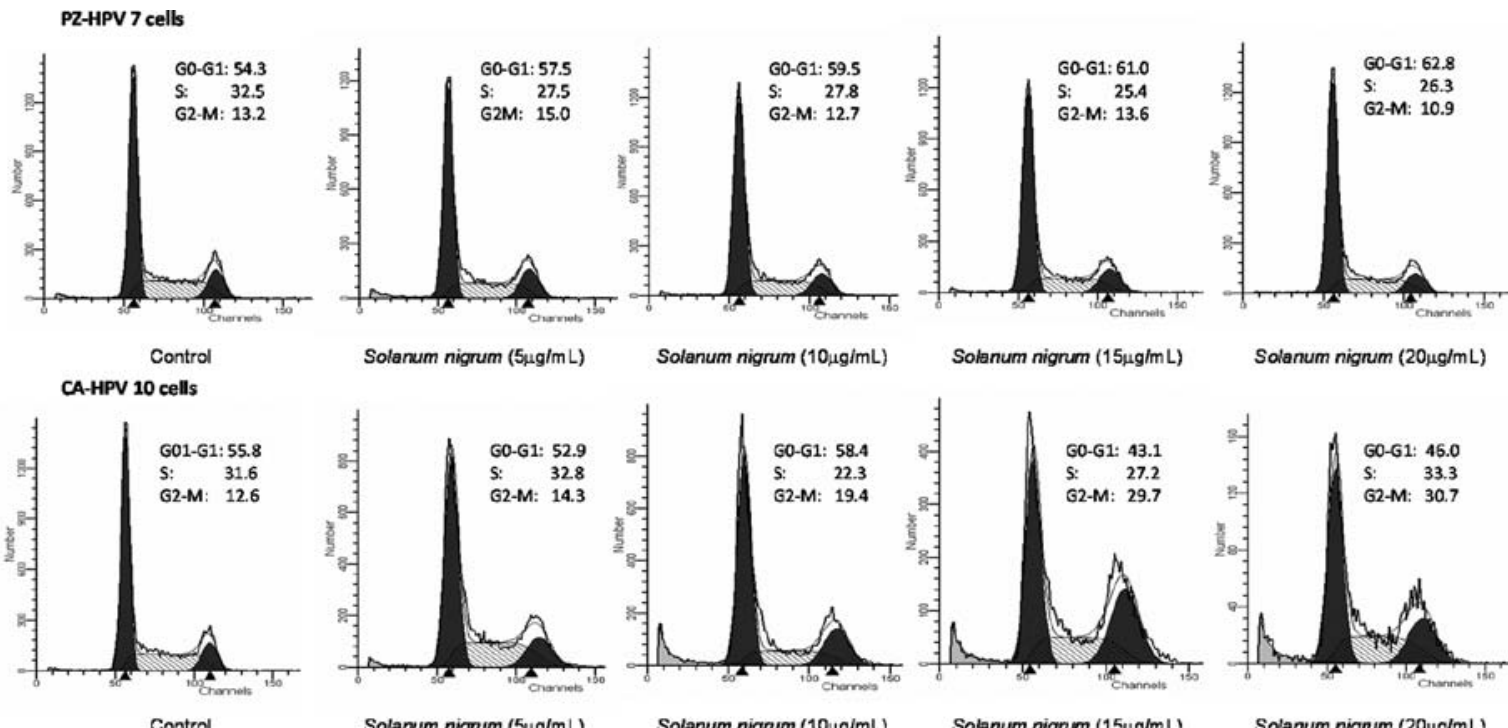

Solanum nigrum $(5 \mu \mathrm{g} / \mathrm{mL})$

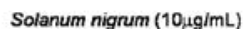

Solanum nigrum $(15 \mu \mathrm{g} / \mathrm{mL})$

Solanum nigrum $(20 \mu \mathrm{g} / \mathrm{mL})$

Figure 4. Effect of SN extract on DNA cell cycle in non-cancerous PZ-HPV-7 cells, and their cancer counterpart CA-HPV-10 cells. Log phase growing cells were exposed to increasing concentrations of SN extract $(5-20 \mu \mathrm{g} / \mathrm{ml})$ in complete medium for $24 \mathrm{~h}$, stained with PI $(50 \mathrm{mg} / \mathrm{ml})$ and analyzed by flow cytometry. Percentages of cells in subG1, G0/G1, S and G2/M phase were calculated using Cell Quest and ModFit cell cycle analysis software, represented in the right side of the histogram. Data shown here are from a representative experiment repeated three times with similar results. The details are described in the Materials and methods section.

prostate cancer CA-HPV-10 cells but not in normal prostate epithelial PZ-HPV-7 cells (Fig. 2C).

We next quantified the extent of apoptosis by measuring the number of TUNEL-positive cells. The PZ-HPV-7 and CA-HPV-10 cells were treated with $5-20 \mu \mathrm{g} / \mathrm{ml}$ concentration of aqueous SN extract for $48 \mathrm{~h}$. Exposure of cells to $\mathrm{SN}$ extract resulted in 4.36\% TUNEL-positive cells at $5 \mu \mathrm{g} / \mathrm{ml}, 15.90 \%$ at $10 \mu \mathrm{g} / \mathrm{ml}, 54.27 \%$ at $15 \mu \mathrm{g} / \mathrm{ml}$ and $55.63 \%$ at $20 \mu \mathrm{g} / \mathrm{ml} \mathrm{SN}$, compared to control (0.26\% stained cells) (Fig. 3). In contrast, a modest percentage of TUNEL-positive stained cells were noted in PZ-HPV cells after similar doses of aqueous SN treatment. Compared to the control group where $0.16 \%$ cells were
TUNEL-positive, exposure to the SN extract caused a modest increase of $3.35 \%$ in the percentage of TUNEL-positive cells at the highest concentration of $20 \mu \mathrm{g} / \mathrm{ml}$ in PZ-HPV-7 cells.

Next we evaluated whether decrease in cell viability and induction of apoptosis in prostate cancer cells by $\mathrm{SN}$ is a result of cell cycle deregulation (Fig. 4). Compared to the control group (12.6\% in $\mathrm{G} 2 / \mathrm{M}$ phase), exposure of prostate cancer CA-HPV-10 cells to the aqueous SN extract resulted in an appreciable arrest of cancer cells in the G2/M phase of the cell cycle after $24 \mathrm{~h}$. The exposure caused an increase accumulation of $14.3 \%$ in the $\mathrm{G} 2 / \mathrm{M}$ phase at a concentration of $5 \mu \mathrm{g} / \mathrm{ml}$, an effect that further increased to $19.4 \%$ at $10 \mu \mathrm{g} / \mathrm{ml}$, 
A
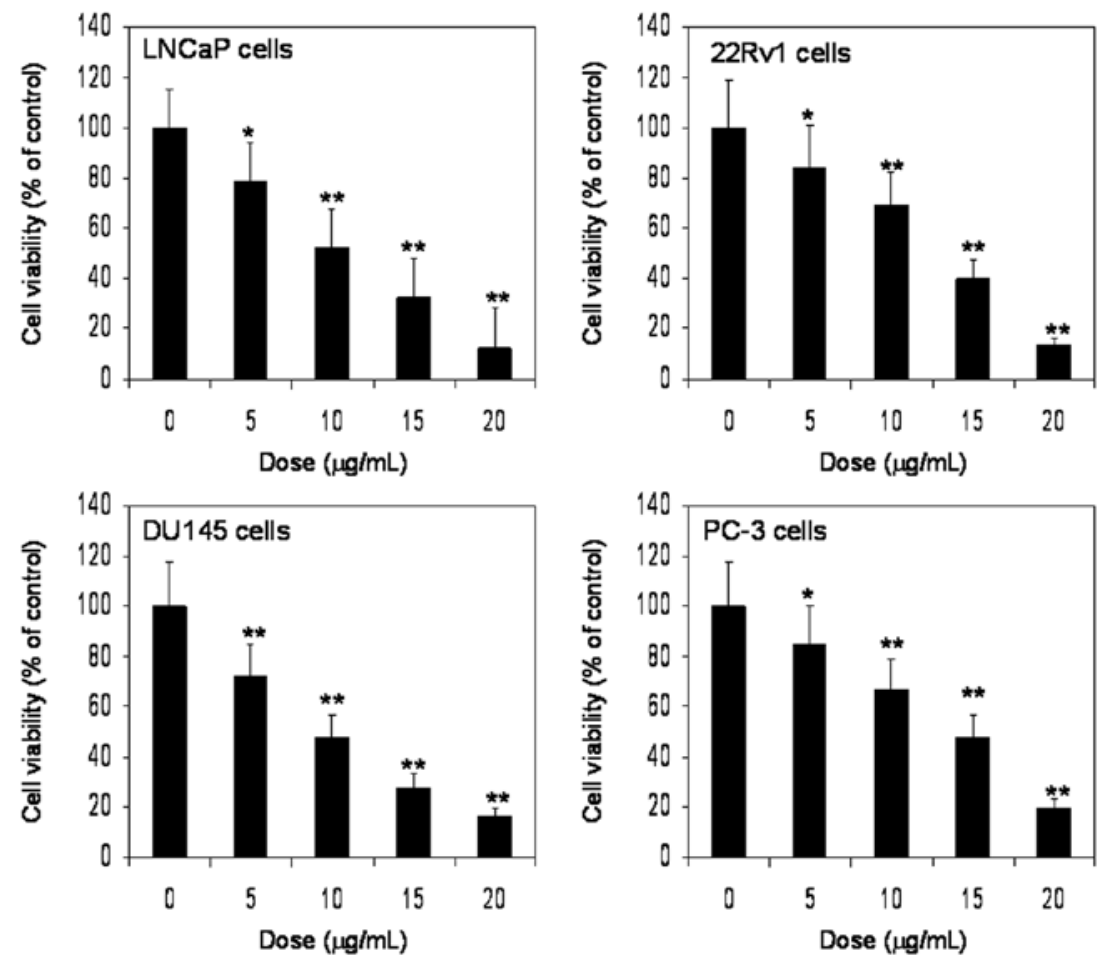

B

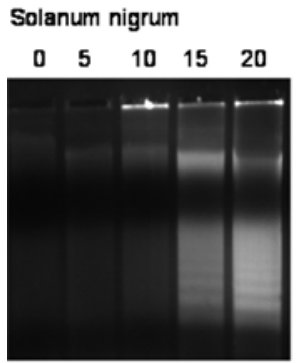

LNCaP cells

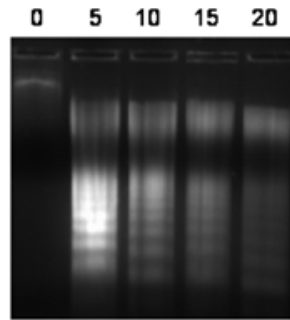

22Rv1 cells

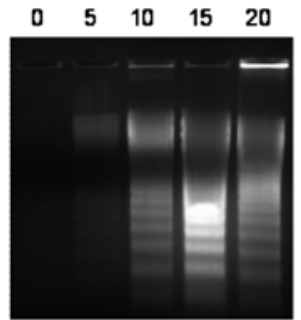

DU145 cells

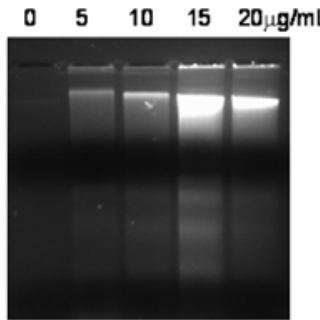

$\mathrm{PC}-3$ cells

Figure 5. Effect of SN extract on cell viability and induction of apoptosis in human prostate cancer 22Rv1, LNCaP, DU145 and PC-3 cells. (A) The cells were exposed to $5-20 \mu \mathrm{g} / \mathrm{ml}$ concentration of SN extract for $24 \mathrm{~h}$, and viability of the cells was determined by the MTT assay. Cell viabilities are depicted as percentages; vehicle-treated cells were regarded as $100 \%$ viable. The values represent mean \pm SD of three different assays in duplicate; ${ }^{*} \mathrm{P}<0.05 ;{ }^{* *} \mathrm{P}<0.001, \mathrm{compared}$ to control. (B) DNA fragmentation assay. The cells were treated with vehicle or 5-20 $\mu \mathrm{g} / \mathrm{ml}$ concentration of SN extract for $48 \mathrm{~h}$, collected for DNA isolation and subjected to agarose gel electrophoresis, followed by visualization of bands under UV light. All prostate cancer cells underwent DNA fragmentation by the SN extract. Details are described in the Materials and methods section.

$29.7 \%$ at $15 \mu \mathrm{g} / \mathrm{ml}$ and $30.7 \%$ at the highest concentration of $20 \mu \mathrm{g} / \mathrm{ml}$ in CA-HPV-10 cells. In contrast, a modest arrest in the G0/G1 phase was noted in PZ-HPV-7 cells after similar doses of aqueous SN treatment. Compared to the control group in which $54.3 \%$ cells were present in the G0/G1 phase, exposure to the SN extract caused an arrest of $62.8 \%$ at the highest concentration of $20 \mu \mathrm{g} / \mathrm{ml}$ in PZ-HPV-7 cells (Fig. 4).

Since prostate cancer is known to be intrinsically heterogeneous and represents a mixture of androgen-responsive and refractory cells at the time of clinical diagnosis, we next investigated the cell growth inhibitory and apoptotic response of aqueous SN extract using cultured cells that broadly represent the spectrum of stages of prostate cancer as well as their response to androgens. A panel of four other human prostate cancer cell lines, the LNCaP (androgen-responsive), 22Rv1 (androgen-repressive), DU145 (androgen-refractory), and PC-3 (androgen-refractory) cell lines were used for evaluating cell growth inhibition and apoptotic response with the SN extract. Exposure of all four cancer cell lines with aqueous SN extract at $5-20 \mu \mathrm{g} / \mathrm{ml}$ concentration resulted in significant decreases in cell viability ranging from $12-88 \%$ and resulted in apoptosis in all the cell lines (Fig. 5). This decrease in cell viability and the apoptotic response of SN extract was not limited to prostate cancer CA-HPV-10 cells as similar treatment resulted in growth inhibition and apoptotic cell death in all the types of prostate carcinoma cells independent of their disease stage and androgen association.

\section{Discussion}

Chemotherapy is one of the major treatment strategies to eliminate residual cancer cells and prevent metastasis after surgery or radiotherapy (18). Chemotherapeutic efficacy or therapeutic index is contingent upon differences during sensi- 
tivity between tumor and normal tissue. The chemotherapeutic indices of known chemotherapeutic agents are often small, with few differences between the doses required for optimal anti-tumor activity which produces severe toxicity to normal tissues (19). The ideal anticancer agent is expected to exert minimal adverse effects to normal tissue and a maximum ability to sacrifice tumor cells and/or inhibit tumor growth. Our studies, for the first time, demonstrate that aqueous polyphenolic rich SN extract possesses maximum anti-tumor effect with minimal toxicity to non-cancerous cells and could potentially play an important role in the therapy or perhaps in the prevention of prostate cancer.

A number of biological pathways can be exploited in the prevention and/or therapy of cancer $(20,21)$. Apoptosis is a physiological process for the elimination of redundant or damaged cells. It is a mode of cell death in which individual cells are deleted from tissue during normal tissue turnover and is characterized by morphological changes including cell shrinkage, membrane blebbing, chromatin condensation, and DNA fragmentation (22). In cancer, resistance to apoptosis affords tumor cells a survival advantage and the ability to be sustained and to proliferate. Apoptosis induction remains arguably the most potent defense against cancer progression as most of the current used chemotherapeutic drugs inhibit cancer cell proliferation by inducing apoptosis $(23,24)$. Unfortunately, chemotherapeutic agents are not designed to selectively target cancer cells. Consequently, chemotherapeutic agents typically damage normal cells, an adverse effect that affects therapeutic modality. Therefore, agents capable of preferably eliminating cancer cells without affecting normal cells offer the safest modality for cancer treatment. Our studies demonstrate a striking difference in the induction of apoptosis after treatment with aqueous SN extract in various human prostate cancer cells representing various disease stages as well as androgen status, compared to non-cancerous cells. These studies further strengthen our findings that the aqueous SN extract could be an effective agent for the treatment of various stages of prostate cancer. Further studies are needed to determine the specific pathways through which the SN extract induces apoptosis in prostate cancer cells.

Uncontrolled cellular proliferation is a hallmark of all cancer, and the blockade of the cell cycle is regarded as an effective strategy for eliminating cancer cells (25). In recent years, many chemotherapeutic agents have been shown to impart anti-proliferative effects via arrest of cell division at certain checkpoints in the cell cycle $(24,25)$. The concept of cell cycle-mediated apoptosis has gained increasing attention as this pathway may provide minimal opportunity for acquired drug resistance, decreased mutagenesis and reduced toxicity (23-25). Our findings on cell cycle analysis indicate that the aqueous SN extract has the ability to induce G2/M phase arrest in prostate cancer CA-HPV-10 cells, indicating that the cells were arrested at the mitotic stage. It will be tempting to decipher which cell cycle regulatory molecules are affected by $\mathrm{SN}$ in prostate cancer cells.

The aqueous extract of SN was observed to be the most effective in causing cytotoxicity to various prostate cancer cells and a minimal effect on non-cancerous cells. The ripe berries of Solanum nigrum contain many steroidal glycosides, steroidal alkaloids and steroidal oligoglycosides, which include solamargine, solasonine, solavilline, solasodamine, solasodine and solanine $(26,27)$. The fruit is rich in polyphenolic compounds including gallic acid, protocatechuic acid, catechins, caffeic acid, epicatechin, rutin and naringenin (28). It is used in traditional folk medicine and shown to possess anti-inflammatory, antipyretic and antioxidant activity (29). A previous study investigated the effect of SN on skin cancer cells, which resulted in inhibition in cell migration and invasion (30). Recent studies demonstrate the anti-proliferative activity of SN in some type of human cancer cells (11-14,30,31). Treatment of human breast cancer MCF-7 and AU565 cells with extracts of fruit and leaves of $\mathrm{SN}$ inhibited cell growth and induced apoptosis and autophagy in these cell lines (32). A $150 \mathrm{kDa}$ glycoprotein isolated from Solanum nigrum L. has been reported to modulate the DNA-binding activities of the transcription factors $\mathrm{NF}-\kappa \mathrm{B}$ and $\mathrm{AP}-1$ and activates the mitochondrial apoptotic pathway in hepatocellular carcinoma, breast, cervical, and colorectal cancer cells (33-36). This protein has reported to have a stimulatory effect on the release of mitochondrial cytochrome c, cleavage of pro-caspase-9, -3, and poly (ADP-ribose) polymerase resulting in apoptosis (36). In in vivo studies using the aqueous $\mathrm{SN}$ extract, inhibition of metastasis in a mouse B16-F1 melanoma xenograft and a lung metastasis model were observed (30). It is suggested that the pronounced anti-proliferative activity of the SN extract on various human prostate cancer cells observed in the present study is critical to uncover the target proteins and to determine the molecular pathways by which SN mediates cancer-specific effects.

In conclusion, for the first time we demonstrate the selective effects of the aqueous SN extract in causing cell cycle arrest and apoptosis in various human prostate cancer cells with minimal effects on normal cells. Our results also show that SN may be an effective herb for the treatment and/or prevention of prostate cancer. Further studies are needed to verify our data and evaluate its effectiveness in preclinical models of prostate cancer. Moreover, an additional study is needed to separate its bioactive components and to evaluate whether the whole mixture or an individual constituent is worthy of further drug development.

\section{Acknowledgements}

The authors thank Mr. R. Michael Sramkoski, Case Comprehensive Cancer Center Core Flow Cytometry, Case Western Reserve University for analyzing cell cycle data. This study was supported by grants from the United States Public Health Services RO1 AT002709 grant and by Endowment funds to S.G.

\section{References}

1. Petrelli A and Giordano S: From single- to multi-target drugs in cancer therapy: when aspecificity becomes an advantage. Curr Med Chem 15: 422-432, 2008.

2. Schwartz GK and Shah MA: Targeting the cell cycle: a new approach to cancer therapy. J Clin Oncol 23: 9408-9421, 2005.

3. Jemal A, Siegel R, Xu J and Ward E: Cancer statistics, 2010. CA Cancer J Clin 60: 277-300, 2010.

4. Wegiel B, Evans S, Hellsten R, Otterbein LE, Bjartell A and Persson JL: Molecular pathways in the progression of hormoneindependent and metastatic prostate cancer. Curr Cancer Drug Targets 10: 392-401, 2010. 
5. Neergheen VS, Bahorun T, Taylor EW, Jen LS and Aruoma OI: Targeting specific cell signaling transduction pathways by dietary and medicinal phytochemicals in cancer chemoprevention. Toxicology 278: 229-241, 2010.

6. Jain R, Sharma A, Gupta S, Sarethy IP and Gabrani R: Solanum nigrum: current perspectives on therapeutic properties. Altern Med Rev 16: 78-85, 2011

7. Raju K, Anbuganapathi G, Gokulakrishnan V, Rajkapoor B, Jayakar B and Manian S: Effect of dried fruits of Solanum nigrum LINN against CCl4-induced hepatic damage in rats. Biol Pharm Bull 26: 1618-1619, 2003

8. Zakaria ZA, Sulaiman MR, Morsid NA, Aris A, Zainal H, Pojan NH and Kumar GH: Antinociceptive, anti-inflammatory and antipyretic effects of Solanum nigrum aqueous extract in animal models. Methods Find Exp Clin Pharmacol 31: 81-88, 2009.

9. Prashanth Kumar V, Shashidhara S, Kumar MM and Sridhara BY: Cytoprotective role of Solanum nigrum against gentamicininduced kidney cell (Vero cells) damage in vitro. Fitoterapia 72 481-486, 2001

10. Jeong JB, De Lumen BO and Jeong HJ: Lunasin peptide purified from Solanum nigrum L. protects DNA from oxidative damage by suppressing the generation of hydroxyl radical via blocking fenton reaction. Cancer Lett 293: 58-64, 2010.

11. Son YO, Kim J, Lim JC, Chung Y, Chung GH and Lee JC: Ripe fruit of Solanum nigrum L. inhibits cell growth and induces apoptosis in MCF-7 cells. Food Chem Toxicol 41: 1421-1428, 2003.

12. Heo KS and Lim KT: Glycoprotein isolated from Solanum nigrum L. modulates the apoptotic-related signals in 12-O-tetradecanoylphorbol 13-acetate-stimulated MCF-7 cells. J Med Food 8: 69-77, 2005.

13. Hsu JD, Kao SH, Tu CC, Li YJ and Wang CJ: Solanum nigrum L. extract inhibits 2-acetylaminofluorene-induced hepatocarcinogenesis through overexpression of glutathione S-transferase and antioxidant enzymes. J Agric Food Chem 57: 8628-8634, 2009.

14. Lin HM, Tseng HC, Wang CJ, Chyau CC, Liao KK, Peng PL and Chou FP: Induction of autophagy and apoptosis by the extract of Solanum nigrum Linn in HepG2 cells. J Agric Food Chem 55 3620-3628, 2007.

15. Bonitati J, Elliott WB and Miles PG: Interference by carbohydrate and other substances in the estimation of protein with the FolinCiocalteu reagent. Anal Biochem 31: 399-404, 1969.

16. Srivastava JK and Gupta S: Antiproliferative and apoptotic effects of chamomile extract in various human cancer cells. J Agric Food Chem 55: 9470-9478, 2007.

17. Wang HC, Chung PJ, Wu CH, Lan KP, Yang MY and Wang CJ Solanum nigrum L. polyphenolic extract inhibits hepatocarcinoma cell growth by inducing G2/M phase arrest and apoptosis. J Sci Food Agric 91: 178-185,2011.

18. Wang ZY, Wang DM, Loo TY, et al: Spatholobus suberectus inhibits cancer cell growth by inducing apoptosis and arresting cell cycle at G2/M checkpoint. J Ethnopharmacol 133: 751-758, 2011.

19. Dawood S and Leyland-Jones B: Pharmacology and pharmacogenetics of chemotherapeutic agents. Cancer Invest 27: 482-488, 2009.

20. Lin Y, Bai L, Chen W and Xu S: The NF-kappaB activation pathways, emerging molecular targets for cancer prevention and therapy. Expert Opin Ther Targets 14: 45-55, 2010.
21. Freemantle SJ, Liu X, Feng Q, et al: Cyclin degradation for cancer therapy and chemoprevention. J Cell Biochem 102: 869-877, 2007.

22. Häcker G: The morphology of apoptosis. Cell Tissue Res 301: 5-17, 2000.

23. Katsman A, Umezawa K and Bonavida B: Chemosensitization and immunosensitization of resistant cancer cells to apoptosis and inhibition of metastasis by the specific NF-kappaB inhibitor DHMEQ. Curr Pharm Des 15: 792-808, 2009.

24. Kögel D, Fulda S and Mittelbronn M: Therapeutic exploitation of apoptosis and autophagy for glioblastoma. Anticancer Agents Med Chem 10: 438-449, 2010.

25. Adhami VM, Aziz MH, Reagan-Shaw SR, Nihal M, Mukhtar H and Ahmad N: Sanguinarine causes cell cycle blockade and apoptosis of human prostate carcinoma cells via modulation of cyclin kinase inhibitor-cyclin-cyclin-dependent kinase machinery. Mol Cancer Ther 3: 933-940, 2004.

26. Ikeda T, Tsumagari H and Nohara T: Steroidal oligoglycosides from Solanum nigrum. Chem Pharm Bull (Tokyo) 48: 1062-1064, 2000.

27. Zhou X, He X, Wang G, Gao H, Zhou G, Ye W and Yao X: Steroidal saponins from Solanum nigrum. J Nat Prod 69: 1158-1163, 2006.

28. Yang MY, Hsu LS, Peng CH, Shi YS, Wu CH and Wang CJ: Polyphenol-rich extracts from Solanum nigrum attenuated PKC alpha-mediated migration and invasion of hepatocellular carcinoma cells. J Agric Food Chem 58: 5806-5814, 2010.

29. Arulmozhi V, Krishnaveni M,Karthishwaran K, Dhamodharan G and Mirunalini S: Antioxidant and antihyperlipidemic effect of Solanum nigrum fruit extract on the experimental model against chronic ethanol toxicity. Pharmacogn Mag 6: 42-50, 2010.

30. Wang HC, Wu DH, Chang YC, Li YJ and Wang CJ: Solanum nigrum Linn water extract inhibits metastasis in mouse melanoma cells in vitro and in vivo. J Agric Food Chem 58: 11913-11923, 2010.

31. Li J, Li Q, Peng Y, Zhao R, Han Z and Gao D: Protective effects of fraction 1a of polysaccharides isolated from Solanum nigrum Linn on thymus in tumor-bearing mice. J Ethnopharmacol 129: 350-356, 2010.

32. Huang HC, Syu KY and Lin JK: Chemical composition of Solanum nigrum Linn extract and induction of autophagy by leaf water extract and its major flavonoids in AU565 breast cancer cells. J Agric Food Chem 58: 8699-8708, 2010.

33. Lee SJ, Oh PS, Ko JH, Lim K and Lim KT: A 150-kDa glycoprotein isolated from Solanum nigrum L. has cytotoxic and apoptotic effects by inhibiting the effects of protein kinase $\mathrm{C}$ alpha, nuclear factor-kappa $\mathrm{B}$ and inducible nitric oxide in HCT-116 cells. Cancer Chemother Pharmacol 54: 562-572, 2004

34. Heo KS, Lee SJ, Ko JH, Lim K and Lim KT: Glycoprotein isolated from Solanum nigrum L. inhibits the DNA-binding activities of NF-kappaB and AP-1, and increases the production of nitric oxide in TPA-stimulated MCF-7 cells. Toxicol In Vitro 18: $755-763,2004$

35. Oh PS and Lim KT: HeLa cells treated with phytoglycoprotein $(150 \mathrm{kDa})$ were killed by activation of caspase 3 via inhibitory activities of NF-kappaB and AP-1. J Biomed Sci 14: 223-232, 2007.

36. Lee SJ and Lim KT: Cell death signal by glycine- and proline-rich plant glycoprotein is transferred from cytochrome $\mathrm{c}$ and nuclear factor kappa B to caspase 3 in Hep3B cells. J Nutr Biochem 19: $166-174,2008$ 